\title{
Detection of Lewy Bodies in Trisomy 21 (Down's Syndrome)
}

\author{
Ravi Raghavan, Clare Khin-Nu, Andrew Brown, Dorothy Irving, Paul G. Ince, \\ Kenneth Day, Stephen P. Tyrer and Robert H. Perry
}

\begin{abstract}
The presence of cortical senile plaques and neurofibrillary tangles sufficient to warrant a neuropathological diagnosis of Alzheimer's disease is well established in middle-aged individuals with Trisomy 21 (Down's syndrome). In contrast a relationship between Down's syndrome and Lewy bodies, one of the major neuropathological features of Parkinson's disease, has not been previously reported. In a cliniconeuropathological survey of 23 cases of Down's Syndrome, two patients, aged 50 and 56 years respectively, were found to have Lewy body formation in the substantia nigra in addition to cortical Alzheimer-type pathology. Neither case showed significant substantia nigra neuron loss although locus coeruleus loss was present in both. Since substantia nigra Lewy bodies are a characteristic neurohistological feature of idiopathic Parkinson's disease, their occurrence in cases of Down's syndrome with evidence of Alzheimer-type pathology supports an aetiopathological connection between Parkinson's disease, Alzheimer's disease, and Down's syndrome; and suggests that common pathogenic mechanisms may underlie aspects of neuronal degeneration in these three disorders, some of which may relate to aberrant chromosome 21 expression.
\end{abstract}

RÉSUMÉ: Détection de corps de Lewy dans la trisomie 21 (syndrome de Down). La présence de plaques séniles corticales et d'amas neurofibrillaires en quantité suffisante pour justifier un diagnostic neuropathologique de maladie d'Alzheimer est bien établie chez les individus d'âge moyen porteurs de la trisomie 21 (syndrome de Down). Par contre, une relation entre le syndrome de Down et les corps de Lewy, une des manifestations neuropathologiques majeures de la maladie de Parkinson, n'a jamais été rapportée dans le passé. Dans une étude cliniconeuropathologique de 12 cas de syndrome de Down, des corps de Lewy ont été retrouvés dans la substance noire de deux patients âgés respectivement de 50 et 56 ans, qui avaient également des manifestations anatomopathologiques corticales de type Alzheimer. Aucun de ces cas n'avait de perte neuronale significative au niveau de la substance noire, bien qu'il y eut des pertes neuronales dans le locus coeruleus chez les deux patients. Comme les corps de Lewy de la substance noire sont une manifestation neurohistologique caractéristique de la maladie de Parkinson, leur existence chez des cas de syndrome de Down avec évidence de pathologie de type Alzheimer supporte qu'il y ait un lien étiopathologique entre la maladie de Parkinson, la maladie d'Alzheimer et le syndrome de Down et suggère que des mécanismes pathogéniques communs pourraient être à la base de certains aspects de la dégénérescence neuronale dans ces trois affections, possiblement en relation avec une expression anormale du chromosome 21 .

Can. J. Neurol. Sci. 1993; 20:48-5I

It is well established that most middle-aged individuals with trisomy 21 (Down's Syndrome) develop neuropathological abnormalities characteristic of Alzheimer's Disease — cortical senile plaques and neurofibrillary tangle formation - which are usually accompanied by a decline in mental function. ${ }^{1 \cdot 3}$ Many similarities have been demonstrated between Alzheimer's Disease and Down's syndrome from clinical, neuropathological, and neurochemical viewpoints. ${ }^{1-4}$ The finding of a common cerebral amyloid protein ( $\beta$ - A4) in cortical plaques in both conditions, ${ }^{5}$ derived from a common precursor molecule (Amyloid Precursor Protein - APP) which maps to chromosome 21, has reinforced an association between these two disorders. Although Lewy body inclusions (accompanied by substantia nigra neuron loss) have been regarded as a hallmark of idiopathic Parkinson's disease,${ }^{6}$ the recent identification of Lewy bodies in elderly demented individuals showing a pattern of Alzheimer-type pathology distinct from Alzheimer's disease - characterized by cortical plaque formation and amyloid deposition, but with few or absent neocortical tangles, and only moderate substantia nigra neuron loss ${ }^{7-9}$ - has both enlarged the spectrum of Lewy body disease $\mathrm{e}^{10}$ and emphasized an association between two of the major neurodegenerative diseases - Alzheimer's and

From the Department of Neuropathology \& MRC Neurochemical Pathology Unit, Newcastle General Hospital, Newcastle-upon-Tyne (R.R., A.B., D.I., P.G.I., R.H.P.); Northgate Hospital, Morpeth, Northumberland (C.K.-N., K.D.); Prudhoe Hospital, Prudhoe, Tyne and Wear (S.P.T.); Department of Psychiatry, University of Newcastle-upon-Tyne (K.D., S.P.T.), United Kingdom

Received June 9, 1992. Accepted in final form September 1, 1992

Reprint requests to: Dr. R. Raghavan, Senior Registrar, Department of Neuropathology, Newcastle-upon-Tyne NE4 6BE, United Kingdom 
Parkinson's disease." The possible association between neuropathological features of Alzheimer's and Parkinson's diseases prompted a neuropathological study to identify Lewy bodies in the brains of middle-aged cases of Down's syndrome.

\section{Materials and Methods}

Brains were obtained from 23 individuals with Down's syndrome over the age of 30 (range 31-74 years) who had died in psychiatric institutions or those for the mentally handicapped in Northumberland. Cases derived from Northgate hospital had been prospectively assessed (CK-N) at regular intervals for evidence of deteriorating mental function and neurological impairment. Control cases $(n=20)$ were derived from age-matched patients dying in Newcastle General Hospital without any evidence of neurological or psychiatric disease. Table 1 shows the sex and age at death of these two groups. The diagnosis of Down's syndrome (of the trisomy 21 type) was based on clinical phenotypic features supplemented by confirmatory chromosome studies available in 17 cases. Neuropathological methods followed those established in Newcastle, ${ }^{7.8}$ senile or neuritic plaque density being quantified on frozen von Braunmühl stained sections $(25 \mu)$ and neurofibrillary tangles being assessed on paraf-

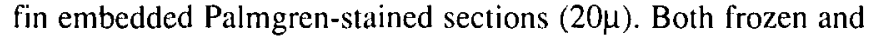
paraffin tissue blocks were taken from standard areas in the four

Table 1: Age (at Death) and Sex of 23 Individuals with Down's Syndrome

\begin{tabular}{|c|c|c|}
\hline & Sex & Age (y) \\
\hline AEL & $M$ & 57 \\
\hline AES & $\mathbf{M}$ & 59 \\
\hline AIN & $\mathrm{F}$ & 33 \\
\hline $\mathrm{Al}$ & $\mathrm{F}$ & 45 \\
\hline BJo & $\mathrm{F}$ & 59 \\
\hline BJa & $M$ & 74 \\
\hline BP & $M$ & 31 \\
\hline $\mathrm{CE}$ & $M$ & 49 \\
\hline CR & $\mathrm{M}$ & 59 \\
\hline CRo & $M$ & 67 \\
\hline $\mathrm{CW}$ & $M$ & 60 \\
\hline DA & $M$ & $56^{*}(\mathrm{LB})$ \\
\hline DI & $M$ & 50 \\
\hline DS & $M$ & 52 \\
\hline GB & $\mathrm{F}$ & 57 \\
\hline GD & $\mathrm{F}$ & 49 \\
\hline $\mathrm{JM}$ & $\mathbf{M}$ & $50^{*}(\mathrm{LB})$ \\
\hline $\mathrm{JT}$ & $\mathrm{M}$ & 57 \\
\hline LB & $\mathrm{F}$ & 54 \\
\hline $\mathrm{MC}$ & $\mathrm{F}$ & 49 \\
\hline $\mathrm{MH}$ & $M$ & 57 \\
\hline OBT & $\mathbf{M}$ & 62 \\
\hline WT & M & 67 \\
\hline
\end{tabular}

*(LB): Case with Lewy Bodies

Controls: For establishing substantia nigra and locus coeruleus neuronal population density control material was obtained from an extended series of neuropsychiatrically assessed normal cases previously described. ${ }^{18}$ cortical lobes, limbic cortex, and hippocampus.. In paraffinembedded material, cresyl fast violet (CFV-20 $\mu$ ) and haematoxylin and eosin (H\&E-6 $\mu$ ) stains were used for neuronal density measurements and the demonstration of Lewy bodies respectively. Lewy body inclusions were additionally stained immunocytochemically with anti-ubiquitin antisera using peroxidase-antiperoxidase techniques previously described. ${ }^{8}$ Limbic and neocortical H\&E sections were screened for cortical Lewy body formation, and since Lewy body inclusions in the brain stem preferentially occur in susceptible nuclei, particularly the substantia nigra, locus coeruleus, and dorsal nucleus of vagus. these nuclei were subject to an intensive screening in all brains: sections being obtained from paraffin-embedded tissue blocks taken from upper and lower midbrain levels containing the substantia nigra; from upper and mid-pontine levels containing the locus coeruleus, and from the mid-medulla. Catecholaminergic neuronal densities within the substantia nigra and locus coeruleus were measured by counting the tolal number of nucleolated neurons in CFV stained sections taken transversely through the brain stem as previously described. ${ }^{\mathrm{s}}$

\section{RESULTS}

Intracyloplasmic Lewy body inclusions were identified in substantia nigra neurons in two of the 23 cases of Down's syndrome, aged 50 years (JM) and 56 years (DA) respectively (Figure 1). Both single and multiple Lewy bodies were present within individual neurons in the two cases, the majority of Lewy bodies being in the pigmented neurons of the pars compacta of the substantia nigra, principally in the A9 subgroup but also within smaller neurons constituting the A10 mesolimbic area close to the interpeduncular fossa. In addition cytoplasmic "pale" bodies typical of those associated with Lewy body pathology were also present. Ubiquitin immunoreactivity was positive in the core region of the Lewy bodies. In the cingulate cortex and hippocampal gyrus occasional cortical Lewy bodies were present (below $0.1 / \mathrm{cm}^{2}$ ), but neocortical (frontal, temporal and parietal lobes) Lewy bodies were only occasionally identified, despite careful screening. Neuronal population densities in the substantia nigra of both individuals were not significantly reduced ( 87 and $59 \%$ of the mean control population respectively in DA and JM); in locus coeruleus and sub-coeruleus neuronal population density was moderately depleted (42 and $52 \%$ of the mean control population in DA and JM respectively) although no Lewy bodies were detected in locus coeruleus. In the neoand archi-cortex, senile plaque density was high in both cases (46.9 and $42.0 / \mathrm{mm}^{2}$ respectively, compared with a mean of $<1$ $/ \mathrm{mm}^{2}$ in controls) and neocortical tangles were readily identified, supporting a neuropathological diagnosis of Alzheimer's disease. Clinically evidence of a dementing process was present in these two cases (assessed by CK-N) and both individuals had exhibited considerable deterioration in speech, memory and self-help skills, and behavioural patterns in the 6-12 months prior to death. Neurological assessment in these two cases had not revealed extrapyramidal features diagnostic of Parkinson:s disease. No other features of Parkinson's disease were identified. A third individual aged 62 years was found to have a single Lewy body in the locus coeruleus. No other Lewy bodics were detected in brain stem nuclei in this patient despite an extensive search, nor were high densities of Lewy bodies detected in the cerebral cortex. Alzheimer-type pathology was mild in this case 
and no associated dementia or extrapyramidal features had been documented prior to death. Since the presence of Lewy body pathology in this case was restricted to one neuron within the locus coeruleus, and could not be confirmed in other neurons or brain stem nuclei, its significance is uncertain at the present time and it has not been included as a definitively positive case in this series.

\section{Discussion}

This investigation has shown that one of the major neuropathological features of Parkinson's disease, neuronal Lewy body inclusions, occur in a proportion $(8.7 \%$ ) of Down's syndrome cases in middle age. Idiopathic Parkinson's disease is characterised neuropathologically by both the presence of Lewy bodies and neuronal loss in brain stem nuclei, particularly the substantia nigra. Nigral cell loss was not advanced in Lewy body-positive cases and nigro-striatal dysfunction had not been associated with severe extrapyramidal symptomatology in either case. In both cases with Lewy bodies there was concomitant neuronal loss in the locus coeruleus, a pattern of brain stem degeneration which is often seen in cases of idiopathic
Parkinson's disease and other neurodegenerative disorders. Although occasional Lewy bodies were identified in the cortex in both cases the neocortical densities were well below densities required to warrant a diagnosis of diffuse Lewy body disease. ${ }^{(0)}$ Previous postmortem studies on Down's syndrome have documented only mild neuronal loss in the substantia nigra apparently associated with high densities of neurofibrillary tangles but not Lewy body inclusions. ${ }^{11,12}$ Neurofibrillary tangles were present in the substantia nigra neurons in the present study, but not in the high densities reported previously. ${ }^{12}$ Future neurochemical studies of striatal dopaminergic activity should clarify the relationship between nigrostriatal dysfunction and extrapyramidal features ${ }^{13}$ in Down's syndrome cases.

An increased prevalence of Lewy bodies in Down's syndrome with Alzheimer-type pathology provides further evidence for a link between the neurodegenerative processes underlying Alzheimer's disease and the spectrum of Lewy body disorders. Immunocytochemical studies of plaques and tangles and Lewy bodies have demonstrated shared antigens, but there is insufficient evidence to confirm common pathogenetic mechanisms in their formation. ${ }^{14.15}$ Wisniewski et al. recently demonstrated that

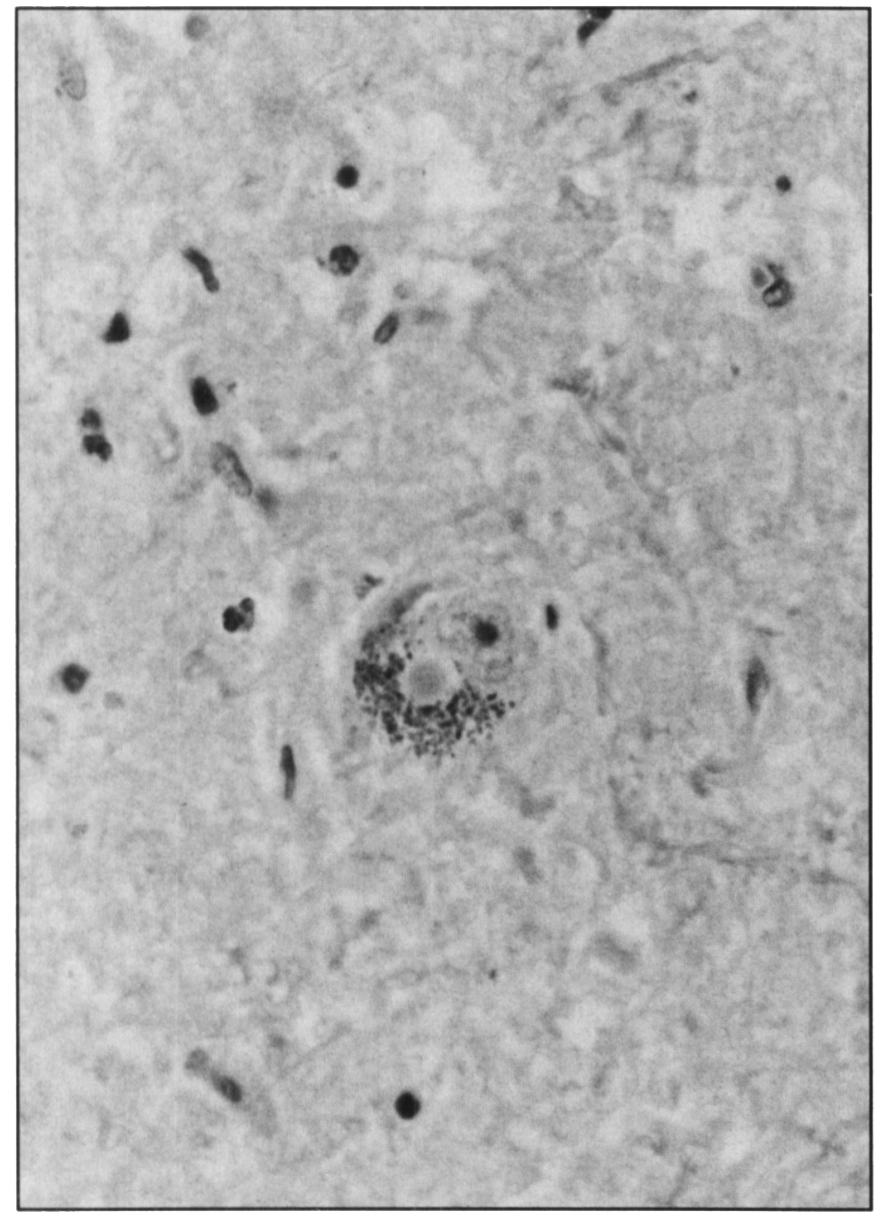

A

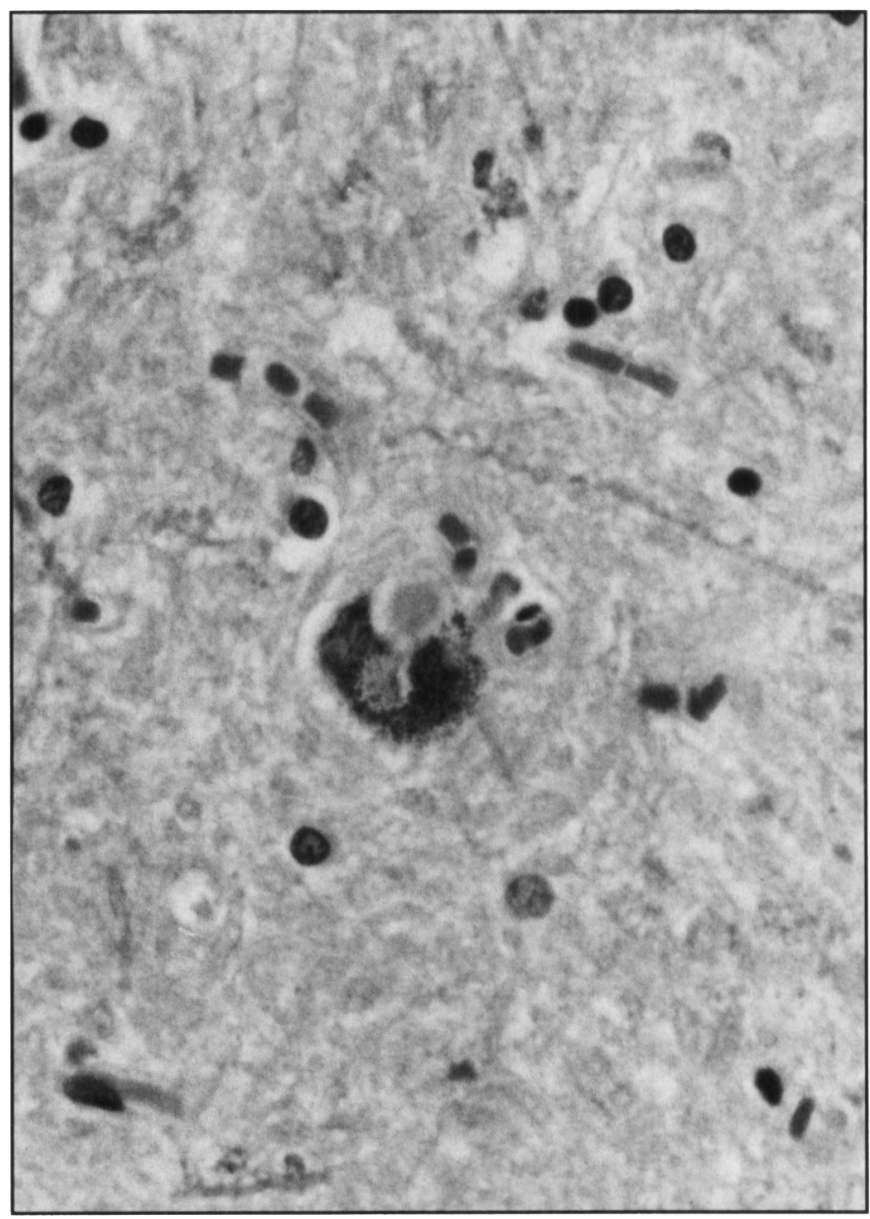

B

Figure 1 - A. Classical Lewy hody with a central eosinophilic core and peripheral halo in a pigmented substantia nigra neuron. The Lewy body lies below the neuronal nucleus with a prominent mucleolus. (Patient DA, 54 years). Magnification $\times 800$. Haematoxlyin and eosin (H\&E) stain. B. Lewy body with an eosinophilic core and peripheral halo in a substantia nigra pigmented neuron. An adjacent pale area partially obscured by neuromelanin pigment represents either a firther Lewy body or a pale body - see results section (Patient JM. 52 years). H\&E stain, Mag X900. 
an antibody raised against the amyloidogenic protein (gelsolinvariant) in familial amyloidosis of the Finnish type has immunoreactivity to Lewy bodies. ${ }^{16}$ The same group subsequently showed that the above antibody had immunoreactivity not only to gelsolin-variant amyloid, but also $\beta$-amyloid in a case of Alzheimer's disease with Lewy bodies. ${ }^{17}$

On current evidence the formation of Lewy bodies in cases of Down's syndrome is unlikely to be a chance or co-incidental occurrence since the prevalence of "incidental" brain stem Lewy bodies in the 6 th decade in the normal population is low $(<1 \%)$, particularly when a population has been screened to exclude cases with neurological or psychiatric disease. ${ }^{18.19}$ It remains to be established however, whether Lewy body inclusions in Down's syndrome represent a primary or direct consequence of the trisomy 21 abnormality, whether they form as a secondary event in brains which are, in an as yet unknown way, susceptible to several neurodegenerative disease processes, ${ }^{19}$ or whether they are formed as an epiphenomenon in a small proportion of patients (around 10\% for Down's syndrome on the basis of the current series) with specific neurodegenerative disorders. An involvement of chromosome 21 in some rare familial cases of Alzheimer's disease has been established by the identification of a missense mutation in the amyloid precursor protein gene (APP 717), ${ }^{20.21}$ which gives rise to a familial dementia syndrome with a range of phenotypic expression but characterized pathologically in the index case by Alzheimer-type pathology and Lewy body formation in the brain stem and cortex. ${ }^{22}$ Other connections between Down's syndrome and Lewy body pathology include the suggestion that the limited nigral degeneration and mild extrapyramidal features in Down's syndrome may relate to raised levels of the enzyme superoxide dismutase, which is regulated by a gene located on chromosome 21,13 and has been implicated in the aetiopathology of Parkinson's disease. ${ }^{23}$ The present findings indicate that chromosome 21 abnormalities which give rise to Down's syndrome may be associated not only with the development of Alzheimer-type pathology in middle age, but also associated, in a proportion of cases, with the development of Lewy bodies.

\section{ACKNOWLEDGEMENTS}

We are grateful to Ms. S. Hammond for her assistance in preparing the manuscript, and to Mr. W. McMeekin for helping us with the illustrations.

\section{REFERENCES}

I. Wisniewski KE, Wisniewski HM, Wen GY. Occurrence of neuropathological changes and dementia of Alzheimer's disease in Down's syndrome. Ann Neurol 1985; 27: 278-282.

2. Wisniewski KE, Dalton AJ, McLachlan C, Wen GY, Wisniewski HM. Alzheimer's disease in Down's syndrome: clinico-pathological studies. Neurology 1985; 35: 957-961.

3. Zelleweger H, Patil SR. Down's syndrome. In: Myrianthopoulos NC, ed. Handbook of Clinical Neurology Vol. 6 (50). Amsterdam: Elsevier Science Publishers, 1987: $519-538$
4. Goodridge H, Reynolds GP, Czudek C, Calcutt NA, Benton M Alzheimer-like neurotransmitter deficits in adult Down's syndrome brain tissue. J Neurol Neurosurg Psychiatry 1987; 50: $775-778$.

5. Glenner GG, Wong CW. Alzheimer's disease and Down's syndrome: sharing of a unique cerebrovascular amyloid fibril protein. Biochem Biophys Res Commun (1984B); 122: 1131-1135.

6. Gibb WRG, Lees AJ. The relevance of the Lewy body to the pathogenesis of idiopathic Parkinson's disease. J Neurol Neurosurg Psychiatry 1988; $51: 745-752$.

7. Perry RH, Irving D, Blessed G, Fairbairn AF, Perry EK. Clinically and neuropathologically distinct form of dementia in the elderly. Lancet 1989; i: 166.

8. Perry RH, Irving D, Blessed G, Fairbairn AF, Perry EK. Senile dementia of Lewy body type. J Neurol Sci 1990; 95: 119-139.

9. Hansen L, Salmon D, Galasko D, et al. The Lewy body variant of Alzheimer's disease: a clinical and pathologic entity. Neurology 1990; 40: 1-8.

10. Perry RH, Irving D, Blessed G, Perry EK, Fairbairn AF. Senile dementia of Lewy body type. and the spectrum of Lewy body disease. Lancet 1989; i: 1086.

11. Gibb WRG, Mountjoy CQ, Mann DMA, Lees AJ. A pathological study of the association between Lewy body disease and Alzheimer's disease. J Neurol Neurosurg Psychiatry 1989: 701708.

12. Gibb WRG, Mountjoy CQ, Mann DMA, Lees AJ. The substantia nigra and ventral tegmental area in Alzheimer's disease and Down's syndrome. J Neurol Neurosurg Psychiatry 1989; 52: 193-200.

13. Vieregge P, Ziemens G, Freudenberg M, et al. Extrapyramidal features in advanced Down's syndrome: clinical evaluation and family history. J Neurol Neurosurg Psychiatry 1991: 54: 34-38.

14. Galloway PG, Grundke-Iqbal I, Iqbal K, Perry G. Lewy bodies contain epitopes both shared and distinct from Alzheimer neurofibrillary tangles. J Neuropathol Exp Neurol 1988; 47: 654 663.

15. Schmidt ML, Murray J, Lee VMY, et al. Epitope map of neurofilament protein domains in cortical and peripheral nervous system Lewy bodies. Am J Pathol 1991; 139: 53-65.

16. Wisniewski T, Haltia M, Ghiso J, Frangione B. Lewy bodies are immunoreactive with antibodies to gelsolin-related amyloidFinnish type. Am J Pathol 1991; 138: 1077-1083.

17. Haltia M, Ghiso J, Wisniewski T, et al. Gelsolin-variant and $\beta$-amyloid co-occur in a case of Alzheimer's with Lewy bodies. Neurobiol Ageing 1991; 12: 313-316.

18. Perry $\mathrm{RH}$, Irving D, Tomlinson BE. Lewy body prevalence in the aging brain: relationship to neuropsychiatric disorders, Alzheimer-lype pathology and catecholaminergic nuclei. J Neurol Sci 1990; 100: 223-233.

19. Smith PEM, Perry RH, Irving D. Density, distribution and prevalence of Lewy bodies in the elderly screened to exclude psychiatric disorders. Neurosci Res Commun 1991: 8: 127-135.

20. St George-Hyslop PH, Haines JL, Farrer LA. et al. Genetic linkage studies suggest that Alzheimer's disease is not a single homogeneous disorder. Nature 1991; 347: 194-197.

21. Chartier-Harlin MH, Crawford F, Houlden H, el al. Early onset Alzheimer's disease caused by mutation at codon 717 of the $\beta$ amyloid precursor protein gene. Nature 1991; 353: 844-846.

22. Lantos PL, Luthert PJ, Hanger D, et al. Familial Alzheimer's disease with the amyloid precursor protein 717 mutation and sporadic Alzheimer's disease have the same cytoskeletal pathology. Neurosci Lett 1992 (in press).

23. Lohr JB. Oxygen radicals and neuropsychiatric illness. Arch Gen Psychiatry 1991; 48: 1097-1106. 